a tumour of the brain would, only a few years ago, have been received with a smile. But we have got beyond this now. Tumours of the brain have been excised, and will be excised again. We are now endeavouring to find out how far we may safely go in this direction. The sine quâ non, in operating on the brain, is of course accurate previous localisation of the lesion, and this the advance of neurological science within the last few years has rendered a comparatively easy task. A careful consideration of the nervous phenomena of the case now enables the expert in neurology to determine with the greatest exactitude both the situation and the probable character of a brain lesion. As regards the former, it can scarcely be anticipated that the boldest surgeon will ever venture beyond the accessible parts of the cortex, but with this limitation enough has already been done to show that brain surgery is destined to occupy an important and legitimate position in the future. It may not yet be possible to predicate, in every case, whether the lesion be situated primarily within the brain substance or on its envelope, nor whether it be inflammatory in character or a neoplasm. I venture to think, however, that the gravity of any case, from a surgical point of view, will depend mostly on the answer which may be given to the former of these two considerations. The latter is probably of less importance, apart from the general question of the comparative curability of inflammatory and neoplastic deposits. Obviously it will be less dangerous to remove an inflammatory thickening of the dura mater or a tumour growing upon it, which simply lies upon, and perhaps has induced some absorption of, the brain substance, than to incise the latter and remove a deposit embedded in its substance. A considerable number of successful cases of the former class of operation have already been recorded, notably by Dr. Macewen, of Glasgow. Of the latter, the original case of Dr. Bennett and Mr. Godlee is the best known, and although unfortunately terminating in death, yet its satisfactory progress for a considerable time showed that the fatal event was due to accidental and preventable causes rather than to anything necessarily inherent to the nature of the case. At the same time, I think I shall be borne out by every surgeon of experience when I say that, while in no department of surgery is a failure of strict antiseptics more likely to be disastrous than when brain matter is exposed, in none is it more difficult to conduct a case through the many pitfalls to which we are exposed to a satisfactory termination. Hence the vast importance of a speedy closure of the wound, which is precisely what cannot be attained in such cases, inasmuch as the cavity resulting from the operation has to fill up by the secondary process of healing.

In connexion with cerebral surgery, I may also allude to the suggestion of Dr. Alexander, of Liverpool, to treat certain cases of epilepsy by ligature of the vertebral arteries. Although his later experience has not quite supported his earlier, yet the proposal, and the partial success which has attended it, afford ground for believing that by surgical means it may be possible to influence materially morbid conditions of the central organ of the nervous system. The employment of nerve-stretching, also, in various forms of peripheral neuroses, is now an established and satisfactory operation, of which you have seen several examples at our meetings.

In thus hastily and imperfectly reviewing the relationship of the surgery of the last few years, considerably fewer than those during which I have been a member of this Society, one cannot but feel that its progress has indeed been a triumphant one. The whole course of the alimentary canal has come within its province, the blood-forming, the secretory, and excretory glands have, every one of them, become the prey of the surgeon's knife. So, to a considerable extent, has the entire circulatory apparatus, and even the seat of the intellect itself. To speculate as to where this will end were vain; for even now the art of surgery is not limited to the mere lopping off and casting away of these failures of the art of medicine. Its influence on the economy is manifest. Can we not cure epilepsy by trephining the skull, and thereby modify the whole future mental state of our patient? Can we not prevent or cure amyloid degeneration by cutting off a suppurating joint, and thereby profoundly alter the whole subsequent nutrition of that child? Can we not prevent the occurrence of the cancerous cachexia and irretrievable ruin by the timely removal of an epithelioma? Can we not believe that in the near future we shall be able to prevent the malignant cachexia of lymphadenosis? Who shall deny that it may be surgery, and not medicine, which shall first show how the development of cancer or of lymphadenosis is to be prevented? May not the spleen be prevented from spoiling the whole mass of blood by a ligature being placed around the splenic artery? Who knows how the congenital predisposition to rheumatism or to gout may not be artificially prevented from declaring itself, and thereby bringing in its train the multitude of secondary ills which its subjects are liable to? How shall "dyspepsia" be treated in the next century? By digesting our food in our stomachs as we do in a test tube, or by a surgical operation on the pancreas? Speculative problems these; but we cannot tell how closely surgery may yet walk hand in hand with medicine and be concerned in the control of the very acts of assimilation and tissue formation.

\section{PRACTICAL REMARKS ON EXTRACTION OF CATARACT.}

Bx ANDERSON CRITCHETT, M.A. CANTAB.,

OPHTHALMIC SURGEON TO, AND LECTURER ON OPHTHALMIC SURGERY AT, ST. MARY'S HOSPITAL.

I BELIEVE that I am not overstating the case when I affirm that before the introduction of cocaine the majority of English ophthalmic surgeons were in the habit of administering an anæsthetic during the operation for extraction of cataract, unless they were able to assure themselves that they had the good fortune to deal with a calm, stoical, and nonspasmodic patient. The advent of the new local anæsthetic has in a great measure broken down our barrier of distrust, and by its aid we are now able to operate successfully on even the most nervous and sensitive of sufferers. But whilst we gretefully recognise the absence of pain which is secured by this valuable agent, we have become aware of certain inconveniencies which, unless duly guarded against, may seriously embarrass an inexperienced operator, and chief amongst these is the partial loss of control over the eyelids which follows on instillation of cocaine, so that the removal of the speculum either after or during an operation for cataract must be accomplished with great care, otherwise a violent spasmodic closure of the lids may produce disastrous results. I can also assure my professional brethren, from personal experience, for I have on more than one occasion kept a speculum in my eye for some minutes, that the forcible separation of the lids by our familiar wire coadjutor produces an almost uncontrollable tendency to squeeze them violently together, and there can be no doubt that the wings of the speculum afford a powerful leverage for the strong spasmodic effort which has so often ruptured a delicate hyaloid membrane and wrecked an otherwise promising operation.

I have therefore adopted a very simple method, which enables me to banish the speculum from all operations for cataract that are performed with cocaine. The chief desideratum is a well-trained and flexible ring-finger. That this digit is too often feeble and not properly under control, is a fact well recognised by pianists and other instrumental executants, and the special exercises that have been devised for its education might also be practised with advantage by ophthalmic surgeons. My plan of operating is as follows:The eye is steadied with forceps held between the thumb and the two first fingers, whilst the ring-finger is used to elevate the upper lid to such an extent as will enable the operator to make the necessary section. The sensitive natural speculum possesses this great advantage-that it can recognise the commencement of a spasmodic effort on the part of the patient and at once give the necessary relaxation, and as the section is nearing its completion the gradual withdrawal of the finger allows the lids to close gently and without effort. If an iridectomy is to be made, the upper lid should be lightly raised at its edge, with the ring-finger of the left hand, whilst the iris is seized with suitable forceps held between the thumb and the first two fingers. It will thus be seen that the operator is able to dispense with the aid both of speculum and assistant. The above plan is so simple and, with a little practice, so easy of accomplishment, that it may very possibly have been already

Read at the annual meeting of the Société Françise d'Ophthalmologie, Paris, April 29th, 1886. 
adopted; but as I have seen no mention of it, and as I have already operated by it successfully in a considerable number of cases both in private and at St. Mary's Hospital, I think it right to put my experiences on record. The cases where this method is most difficult of application are those in which the eyes are small and deeply seated, but a little extra patience and care on the part of the operator will surmount these obstacles; and, on the other hand, it is specially suitable for prominent eyes, where the use of the speculum has so often proved hazardous. The knife with which I operate differs somewhat in shape from Graefe's original pattern. It will be seen from Fig. 1 that the blade begins to broaden rapidly immediately below the point, which is central; the back of the knife is bevelled and the blade is rounded, so that in this respect it resembles the

FIG. 1.

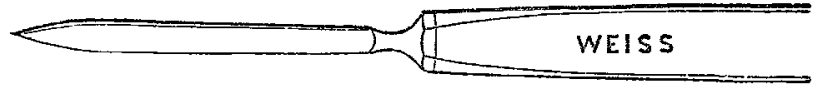

Beer's knife, and does not permit a too rapid escape of aqueous. My knife is broader than those in general use; indeed, I understand that several of our foremost operators, both here and on the Continent, now prefer an extremely narrow blade. I have tried every variety of pattern, and have finally decided in favour of that which $I$ have above described, because I find that it facilitates the accomplishment of a smooth and rapid section, and that the iris is less liable to fall in front of the edge of the knife than is the case with more attenuated blades. In making my section, I seize the subconjunctival tissue with forceps just below the spot where I intend to make my counter-puncture. I by no means follow the direction given in some of the textbooks to make the puncture and counter-puncture exactly at the same level, because the adoption of that method

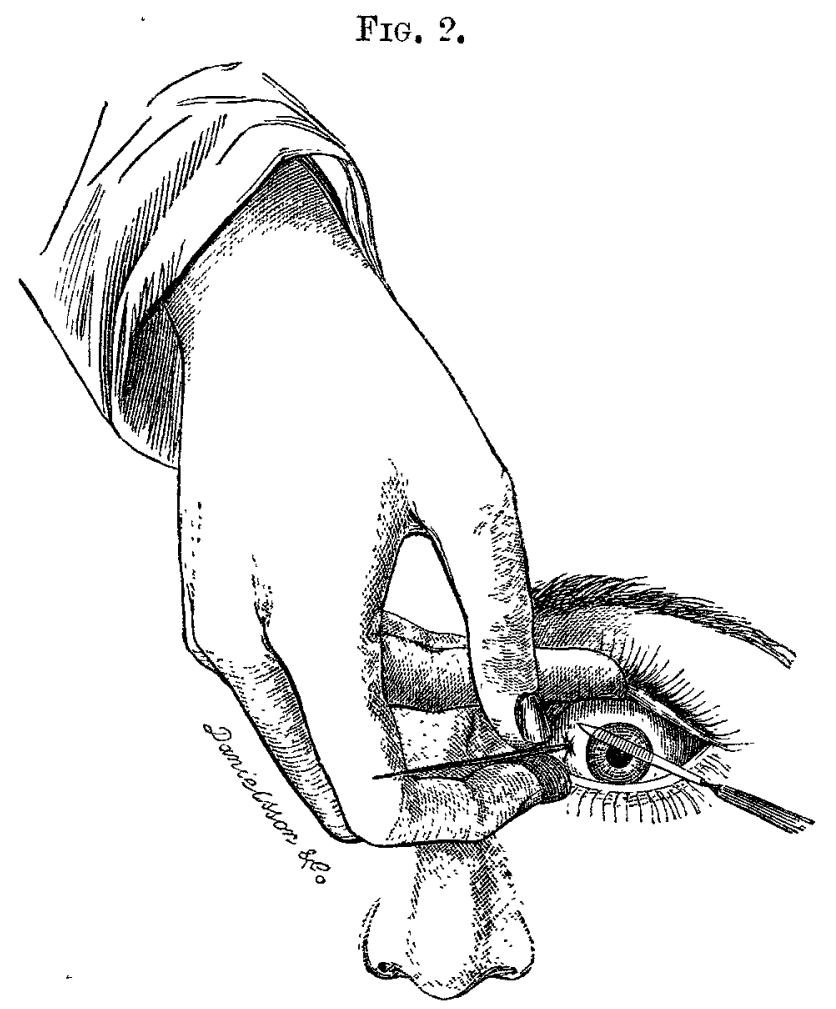

necessitates the immediate commencement of a sawing movement, which drags upon the globe, and must of necessity leave an objectionable serrated edge to the flap. I am careful to introduce my knife at a lower level than that at which the counter-puncture is to be made (vide Fig. 2). The moment that the point emerges, an upward and onward sliding movement imparted to the knife will enable threefourths of the section to be smoothly completed before any backward motion need be employed, and the least possible amount of violence is thus done to the internal economy of the eye. After the capsule is ruptured, I gently depress the upper edge of the section to prevent it from impeding the exit of the cataract, and if the latter should refuse to quit its home after the exhibition of moderate pressure, I am frequently able to rotate it out by applying a curette to the margin of its under surface. These and other equally useful mancuvres are doubtless well known to all experienced ophthalmic surgeons, but I venture to hope that a trial will be made of the plan I have described, in which, in suitable cases, nature's speculum takes the place of that which we have hitherto used.

\section{ON A NEW METHOD OF ESTIMATING THE CONDITION OF THE RIGHT SIDE OF THE HEART.}

BY W. PASTEUR, M.D. LOND, M.R.C.P.,

PHYSTCIAN TO THE NORTH-EASTERN HOSPITAT FOR CHILDREX, ANI MEDYCAL REGISTRAR TO THE MIDDLESEX HOSPITAL.

IN September, 1885, I called attention ixs the columns of THe LanCET to a distension of the superficial veins of the neck which occurs when, under certain circumstances, pressure is exerted over the liver. I have since then had the opportunity of examining a large number of patients presenting both positive and negative instances of this phenomenon, with results of sufficient interest to be worth recording. The physical sign in question is a distension or over-filling of the external jugular veins, apparently from below, with or without pulsation or undulation, which takes place when pressure is exerted in the right hypochondriac or epigastric regions with the flat of the hand, the direction of pressure being backwards and upwards. Before proceeding to make the examination the patient should be placed in the recumbent posture, with the neck slightly extended and the head turned a little to one side, while care is taken that the muscles of the neck are not in a state of tension. The sign is usually best marked on the right side, but may in almost every case be demonstrated on the left side also. It is essential that the movements of respiration should be normally maintained throughout the examination. I have frequently observed a partial filling-in of the supraclavicular fossa at the moment when pressure is first exerted. This is especially marked in thin subjects, and may be accounted for to some extent, perhaps, by simple mechanical displacement, but is, $I$ believe, chiefly due to an involuntary arrest or modification of breathing, and almost invariably subsides in a few moments. The amount of pressure required varies in different individuals. In rare cases rigidity of the abdominal muscles renders the manceuvre quite impossible. The presence of moderate ascites is no impediment, but excessive distension of the abdomen with fluid or gas renders the necessary manipulation more difficult and sometimes impossible. The pressure should be exercised gradually and steadily, otherwise an attack of coughing is liable to be induced, particularly in cases of bronchitis. The patients rarely complain of any pain or even discomfort, but on the occurrence of the least pain the manipulation should be at once discontinued. The following case affords a good illustration of the phenomenon.

L. W- aged thirty, was admitted into the Middlesex Hospital in October, 1885, suffering from intense dyspnœea. The face was cyanosed, the lips very blue, and the breathing very rapid and shallow. There was moderate distension of the external jugular veins, which pulsated distinctly and filled from below. Over the heart's apex there was a short systolic bruit, with a line if conduction towards the axilla. The heart dulness was increased towards the right; the liver was not enlarged. Pressure exerted in the right hypochondriac and epigastric regions immediately produced a very marked alteration in the jugular veins. They became very visibly distended, the pulsation at the same time becoming less obvious, and shifting to a spot higher up the vein. This alteration in the condition of the veins persisted as long as the pressure was maintained, but on remoring the hand these at once returned to their former state. The patient was treated with full doses of digitalis. On the third day there was a marked improvement in her general condition. The breathing had become natural and all trace of venous pulsation and distension had disappeared. Firm pressure applied as before was now entirely without effect on the veins. Once or twice a scarcely perceptible filling of them below the valves was observed, which was probably due to a slight modification in the breathing.

With a single excertion, to which I shall refer again, this 